JKKP: Jurnal Kesejahteraan Keluarga dan Pendidikan

http://doi.org/10.21009/JKKP

DOI: doi.org/10.21009/JKKP.012.09

E-ISSN: 2597-4521

\title{
Perbandingan Prestasi Belajar Berdasarkan Gaya Belajar Mahasiswa
}

\author{
Tarma \\ tarmasae@gmail.com \\ Pendidikan Kesejahteraan Keluarga, IImu Kesejahteraan Keluarga \\ Fakultas Teknik, Universitas Negeri J akarta \\ J In. Rawamangun Muka, J akarta Timur. 13220
}

\begin{abstract}
Abstrak
Tujuan dari penelitian ini adalah untuk membandingkan prestasi belajar mahasiswa berdasarkan gaya belajarnya. Dalam penelitian ini, prestasi belajar yang digunakan sebagai data adalah prestasi belajar dalam mata kuliah evaluasi pembelajaran. Sementara gaya belajar diklasifikasikan ke dalam empat kelompok, yaitu converger, diverger, assimilator, dan accommodator sesuai dengan teori yang dikemukakan oleh Kolb. Sumber data dalam penelitian ini adalah mahasiswa Program Studi Pendidikan Kesejahteraan Keluarga angkatan 2012 yang mengambil mata kuliah Evaluasi Pembelajaran sebanyak 43 orang. Hasil analisis data dengan menggunakan metode One Way Anova diketahui bahwa tidak terdapat perbedaan prestasi antara berbagai jenis gaya belajar.
\end{abstract}

Kata kunci: prestasi belajar, gaya belajar, evaluasi pembelajaran.

\section{Student Achievement Comparison Based on Learning Styles}

\begin{abstract}
The purpose of this study was to compare the achievement of students based on their learning styles. In this study, academic achievement that is used as the data is in the course of learning achievement evaluation of learning. While learning styles are classified into four groups, namely converger, diverger, assimilator, and accommodator according to the theory proposed by Kolb. Source of data in this study were 43 students of Family Welfare Education which took courses Learning Evaluation. The results of data analysis using One Way ANOVA is known that there aren't differences in achievement between different types of learning styles
\end{abstract}

Keyword: learning achievement, learning style, learning evaluation. 


\section{PENDAHULUAN}

Belajar merupakan proses yang dilakukan individu untuk meningkatkan pengetahuan sikap dan keterampilan sesuai dengan tujuan belajar yang ingin dicapai. Setelah melakukan proses belajar dalam rentang waktu tertentu, maka akan diperoleh pengetahuan, sikap dan keterampilan tertentu. Pengetahuan, sikap dan keterampilan yang diperoleh atau dimiliki peserta didik setelah melakukan kegiatan belajar disebut hasil belajar.

Perkuliahan merupakan salah satu proses belajar dan pembelajaran. Dalam perkuliahan, mahasiswa melakukan proses belajar melalui berbagai aktivitas, seperti membaca referensi, menyimak penjelasan dosen, mempraktikkan suatu konsep, melakukan pengamatan dan sebagainya. Di sisi lain, dalam perkuliahan, dosen melakukan kegiatan pembelajaran, yaitu proses mengarahkan, mendorong, membimbing, dan menginspirasi agar terjadi proses belajar pada peserta didik.

Salah satu mata kuliah dasar kependidikan (MKDK) yang wajib ditempuh oleh mahasiswa ialah Mata Kuliah Evaluasi Pembelajaran. Mata kuliah ini membahas tentang hakikat evaluasi pembelajaran yang meliputi konsep dasar evaluasi, tujuan, fungsi, peranan, dan prinsip-prinsip evaluasi. Di samping itu, diharapkan juga mahasiswa dapat memahami dan menerapkan langkah pengembangan instrumen evaluasi pembelajaran, praktik penulisan butir soal, pengolahan data hasil evaluasi, analisis kualitas alat hasil evaluasi (validitas dan reliabilitas), analisis kualitas butir soal (tingkat kesulitan, daya pembeda, dan keberfungsian distraktor), pemanfaatan hasil kegiatan evaluasi pembelajaran (feedback untuk perbaikan program dan proses pembelajaran, diagnostik kesulitan belajar dan penempata posisi siswa dalam kelas).

Perkuliahan ini bersifat teoritis dan praktis. Mahasiswa dituntut untuk mengetahui, memahami, menerapkan, menganalisis, dan mengevaluasi berbagai teori tentang evaluasi pembelajaran. Setelah menguasai teori, mahasiswa dituntun untuk membuat perangkat evaluasi pembelajaran seperti soal objektif (seperti soal pilihan ganda, menjodohkan, melengkapi). Setelah berhasil menyusun perangkat evaluasi, mahasiswa juga diharuskan untuk menguji dan menganalisis perangkat evaluasi yang telah disusunnya. Pengujian dan analisis dimaksud meliputi uji validitas, uji reliabilitas, analisis daya, analisis tingkat kesukaran item dan analisis distraktor. Sehinga pada akhirnya diharapkan mahasiswa memiliki kemampuan yang mumpuni dalam evaluasi pembelajaran, khususnya evaluasi pembelajaran pada mata pelajaran yang terkait dengan bidang ilmu pendidikan kesejahteraan keluarga.

Perkuliahan dalam Mata Kuliah Evaluasi pembelajaran dilakukan dengan beberap metode, yaitu ceramah, diskusi, penugasan, tutorial, dan praktik. Melalui berbagai metode yang diterapkan tersebut diharapkan penguasaan atau hasil belajar yang dicapai lebih optimal.

Hasil belajar yang diperoleh mahasiswa merupakan output yang sangat diperhatikan. Berdasarkan kajian literature, hasil belajar tidak hanya ditentukn oleh beberapa faktor. Syah (2013:145) menyebutkan bahwa ada tiga faktor yang mempengaruhi belajar, yaitu:

1. Faktor internal atau faktor yang berada dalam diri peserta didik, yakni keadaan/kondisi jasmani dan rohani siswa yang mencakup fisiologis dan psikologis (intelegensi, sikap, bakat, minat, motivasi).

2. Faktor eksternal atau faktor dari luar pesert didik, yakni kondisi lingkungan di sekitar peserta didik, meliputi lingkungan sosial, lingkungan nonsosial

3. Faktor pendekatan belajar (approach to learning), yakni jenis upaya peserta didik yang meliputi strategi dan metode yang digunakan oleh peserta didik untuk melakukan kegiatan pembelajaran.

Pendekatan belajar atau dalam artikel ini dikhususkan sebagai gaya belajar merupakan salah satu faktor yang menentukan keberhasilan seseorang dalam melakukan kegiatan belajar.

Banyak teori dan ahli yang mengungkapkan tentang gaya belajar. dalam penelitian ini, gaya belajar merujuk pada pendapat David Kolb. David Kolb sebagaimana dikutip oleh Suyono dan Hariyanto (2013) membagi gaya belajar ke dalam empat kategori sebagai berikut: 
1) Gaya converger. Peserta didik yang memiliki gaya belajar ini dicirikan oleh kemampuan dalam melakukan konseptualisasi abstrak dan pengalaman aktif. Peserta didik terampil dalam melaksanakan aplikasi praktis dari gagasannya dan menggunakan logika deduktif untuk memecahkan masalah. Supaya pembelajaran terhadap peserta didik dengan gaya belajar ini lebih efektif, guru harus bertindak sebagai motivator.

2) Gaya diverger. Peserta didik yang memiliki gaya belajar ini dicirikan oleh kemampuan konseptualisasi abstrak dan pengalaman reflektif. Peserta didik dengan gaya belajar tipe ini merespon informasi yang diberikan dengan baik jika mereka diberi waktu untuk melakukan refleksi. Supaya kegiatan pembelajaran pada peserta didik dengan tipe belajar diverger berjalan efektif, guru harus berperan sebagai pakar (expert).

3) Gaya assimilator. Peserta didik yang memiliki gaya belajar ini dicirikan dengan kemampuan konseptualisasi abstrak dan pengalaman reflektif. Peserta didik dengan gaya belajar ini terampil membangun model teoritis dengan cara penalaran induktif. Agar pembelajaran efektif, guru harus bertindak sebagai pelatih (coach).

4) Gaya accommodator. Peserta didik yang memiliki gaya belajar ini dicirikan dengna penggunaan pengalaman konkret dan eksperimentasi aktif. Pesreta didik mampu secara aktif mengaitkan dunia nyata dengan pembelajaran yang dilakukannya,lebih aktif melakukan sesuatu disbanding sekedar membaca atau mempelajarinya dari buku. Peserta didik dengan gaya belajar ini dapat menerapkan materi pembelajaran dalam situasi nyata untuk memecahkan masalah keseharian. Untuk pembelajaran terhadap peserta didik dengan tipe belajar ini, guru harus memberikan keleluasaan dan mengoptimalkan kesempatan peserta diidk untuk menemukan sesuatu yang berarti bagi dirinya sendiri. Peran guru yaitu sebagai fasilitator.

Setiap mata kuliah memiliki karakteristik yang berbeda dengan mata kuliah yang lain. Pernedaan tersebut dapat dilihat dari karakteristik materi perkuliahan, metode pembelajaran yang dilakukan oleh dosen, proses dan prosedur pembelajaran, sumber belajar yang dignakan, serta tuntutan cara belajar yang harus dilakukan oleh mahasiswa agar optimal mencapai hasil belajarnya. Khusus mengenai cara mahasiswa mempelajari mata kuliah evaluasi pembelajaran, dimensinya menjadi sangat personal dan beragam. Dimensi yang dikaji dalam penelitian ini adalah dimensi gaya belajar diverger, konverger, asimilator, dan akomodator. Berdasarkan pengelompokkan mahasiswa menurut keempat gaya belajar tersebut, apakah terdapat perbedaan yang signifikan dalam hasil belajarnya. Kemudian, gaya belajar apakah yang menunjukkan hasil belajar yang optimal. Sebaliknya, gaya belajar yang manakah yang hasil belajarnya paling tidak optimal. Berdasarkan hasil penelitian ini diharapkan diketahui jenis gaya belajar yang sangat tepat untuk Mata Kuliah Evaluasi Pembelajaran. Untuk selanjutnya dapat dilakukan upaya untuk membantu mahasiwa dengan gaya belajar yang kurang sesuai dengan mata kuliah ini.

\section{METODE PENELTIAN}

Penelitian ini menggunakan metode penelitian deskriptif komparatif. Populasi dalam penelitian ini adalah mahasiswa Program Studi Pendidikan Kesejahteraan Keluarga Angkatan 2012 yang mengambil Mata Kuliah Evaluasi Pembelajaran pada semester 100 (Pebruari-Juni 2014). Adapun jumlah sampel yang diambil sebanyak 43 mahasiswa. Identifikasi gaya belajar menggunakan instrumen terstandar tentang identifikasi gaya belajar menurut David Kolb. Sementara data tentang hasil belajar mahasiswa diperoleh melalui tes hasil belajar yang meliputi tes objektif (pilihan ganda), tes subjektif, tes penyusunan soal dan analisis/pengujian soal. Teknik analisis data menggunakan analisis komparatif dengan One Way Anova. 


\section{HASIL DAN PEMBAHASAN}

Berdasarkan hasil penelitian, diketahui bahwa dari dari 43 mahasiswa terbagi ke dalam empat gaya belajar, yaitu: 10 orang $(23,3 \%)$ dengan gaya belajar akomodator, 4 orang $(9,3 \%)$ dengan gaya belajar kolaborator, 12 orang $(27,9 \%)$ dengan gaya belajar diverger, dan 17 orang $(39,5 \%)$ dengan gaya belajar konverger. Secara jelas dapat dilihat dalam grafik di bawah ini.

Tabel 1. Karakteristik Gaya Belajar Responden

\begin{tabular}{clcc}
\hline No. & Gaya Belajar & Jumlah & $\%$ \\
\hline 1 & Akomodator & 10 & $23.3 \%$ \\
2 & Asimilator & 4 & $9.3 \%$ \\
3 & Diverger & 12 & $27.9 \%$ \\
4 & Konverger & 17 & $39.5 \%$ \\
\hline & Jumlah & 43 & $100 \%$
\end{tabular}

Berdasarkan pada tabel di atas, diketahui bahwa gaya belajar yang paling dominan dimiliki oleh mahasiswa ialah gaya belajar konverger. Sementara gaya belajar yang paling sedikit ialah gaya belajar kolaborator. Perbandingan jumlah gaya belajar tersebut ditunjukkan dengan grafik di bawah ini (Grafik 1).

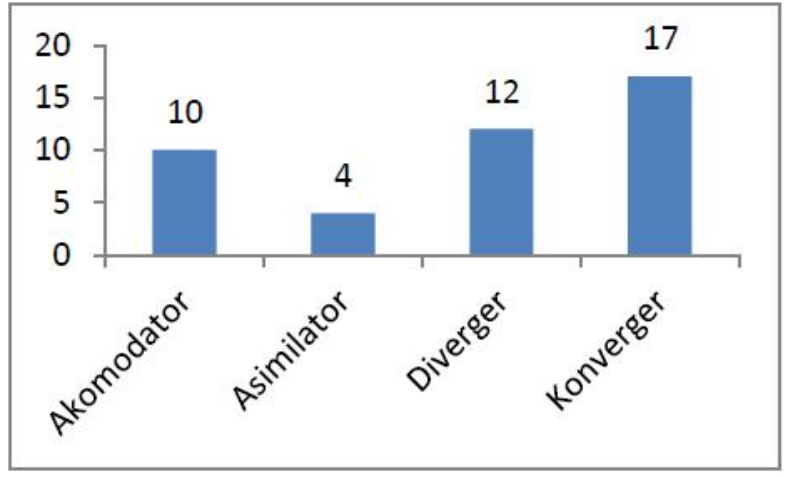

Grafik 1. Perbandingan Jumlah Gaya Belajar

Berdasarkan hasil tes evaluasi pembelajaan, diketahui rata-rata nilai akhir mahasiswa dalam Mata Kuliah Evaluasi Pembelajaran. Rata-rata nilai hasil belajar yang paling lemah ditunjukkan oleh mahasiswa yang memiliki gaya belajar konverger, yakni 78,36. Sementara gaya belajar dengan rata-rata nilai hasil belajar tertinggi yaitu pada mahasiswa yang memiliki gaya belajar diverger, yaitu sebesar 80,40. Hasilnya ditunjukkan dalam tabel di bawah ini (Tabel 2).

Tabel 2. Rata-Rata Nilai Hasil Belajar

\begin{tabular}{clc}
\hline No. & Gaya Belajar & Rata-rata \\
\hline 1 & Akomodator & 79.75 \\
2 & Asimilator & 79.73 \\
3 & Diverger & 80.40 \\
4 & Konverger & 78.36 \\
\hline
\end{tabular}

Secara ilustratif, perbandingan rata-rata nilai hasil belajar dalam Mata Kuliah Evaluasi Pembelajaran ditunjukkan dalam grafik di bawah ini (Grafik 2). 


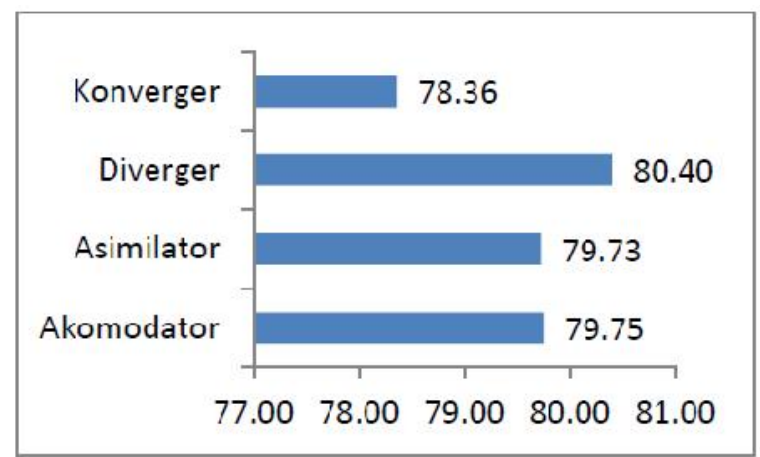

Grafik 2. Perbandingan Nilai Rata-Rata

Berdasarkan analisis data dengan menggunakan metode One Way Anova diketahui nilai $F$ hitung sebesar 0,43 dan $F$ tabel sebesar 2,84. Karena $F$ hitung < dari $F$ tabel maka dapat disimpulkan bahwa tidak terdapat perbedaan yang signifikan di antara keempat gaya belajar (akomodator, kolaborator, diverger, konverger).

Berdasarkan pada hasil penelitian ini, ada beberapa hal yang dapat dibahas lebih lanjut yang diuraikan sebagai berikut.

Pertama, rata-rata hasil belajar tertinggi ditunjukkan oleh mahasiswa yang memiliki gaya belajar diverger. Mahasiswa dengan gaya belajar diverger memiliki kemampuan konseptualisasi abstrak dan pengalaman reflektif. Dalam memahami konsep evaluasi pembelajaran diperlukan keterampilan konseptualisasi abstrak. Hal yang sama juga dibutuhkan dalam menyusun instrumen evaluasi, di mana mahasiswa harus mencermati silabus (kompetensi inti, kompetensi dasar, tujuan pembelajaran, indikator pembelajaran, materi pembelajaran, dsb), mempelajari bahan ajar, menentukan jenis instrument evaluasi yang tepat, menyusun instrumen evaluasi pembelajaran dan melakukan pengujian dan analisis instrumen yang telah dibuat. Hal-hal tersebut memerlukan kemampuan dan gaya belajar yang dapat mengkonseptualisasi abstrak. Ciri lain dari gaya belajar ini adalah melakukan refleksi. Dalam mempelajari mata kuliah evaluasi pembelajaran ini diperlukan keterampilan merefleksikan secara mendalam tentang instrumen yang telah disususn, apakah sudah tepat, sudah memadai, sesuai dengan kaidah penyusunan soal, dan sebagainya.

Kedua, rata-rata hasil belajar yang paling rendah ditunjukkan oleh mahasiswa dengan gaya belajar konverger. Hal yang menarik adalah bahwa mahasiwa yang memiliki gaya belajar ini dicirikan oleh kemampuan dalam melakukan aktif. Dalam mata kuliah ini, banyak sekali penggunaan logika deduktif, dan aplikasi praktis. Meskip memiliki gaya belajar yang secara konseptual sangat relevan dengan karakteristik mata kuliah evaluasi pembelajaran, namun ternyata hasil belajarnya belum optimal. Perlu dikaji lebih lanjut faktor apakah yang mempengaruhi mahasiswa dengan gaya belajar konverger sehingga menyebabkan rata- rata hasil belajarnya paling rendah.

Ketiga, untuk memfasilitasi pembelajaran agar hasil belajar di antara keempat gaya belajar tersebut, masih diperlukan formula pembelajaran yang lebih tepat, diperlukan penelitian lebih lanjut.

\section{KESIMPULAN}

Berdasarkan hasil penelitian yang telah diuraikan di atas, dapat disimpulkan beberapa hal sebagai berikut:

1. Tidak terdapat perbedaan yang signifikan dalam hasil belajar Mata Kuliah Evaluasi Pembelajaran di antara gaya belajar akomodator, kolaborator, diverger dan konverger.

2. Rata-rata hasil belajar Mata Kuliah Evaluasi Pembelajaran tertinggi ditunjukan oleh mahasiswa yang memiliki gaya belajar diverger.

3. Rata-rata hasil belajar Mata Kuliah Evaluasi Pembelajaran terendah ditunjukan oleh mahasiswa yang memiliki gaya belajar konverger 


\section{DAFTAR PUSTAKA}

Akdon dan Hadi. 2005. Aplikasi Statistika dan Metode Penelitian Untuk Administrasi dan Manajemen. Bandung: Dewa Ruchi.

Gredler, M.E.B. 1991. Belajar dan Membelajarkan. Jakarta: CV Rajawali.

Siregar, E., dan Nara, H. 2011. Teori Belajar dan Pembelajaran. Bogor: Ghalia Indonesia.

Suyono dan Hariyanto. 2013. Belajar dan Pembelajaran. Bandung: Remaja Rosdakarya.

Syah, M. 2013. Psikologi B elajar. Jakarta: Raja Grafindo Persada.

Widiyanto, M. A. 2013. Statistika Terapan. Jakarta: Elex Media Komputindo. 